\title{
CENTROS DE MEMÓRIA DA EDUCAÇÃO FÍSICA E ESPORTE DAS UNIVERSIDADES FEDERAIS BRASILEIRAS: PRESERVAR MEMÓRIAS PARA RECONSTRUIR HISTÓRIAS
}

\author{
MEMORY CENTERS FOR PHYSICAL EDUCATION AND SPORTS IN BRAZILIAN \\ UNIVERSITIES: PRESERVING MEMORIES TO REBUILD STORIES
}

CENTROS DE MEMORIA DE EDUCACIÓN FÍSICA Y DEPORTE DE LAS UNIVERSIDADES FEDERALES BRASILEÑAS: PRESERVAR MEMORIAS PARA RECONSTRUIR HISTORIAS

\section{Christiane Garcia Macedo*, Silvana Vilodre Goellner**}

\section{Palavras chave:} História. Educação Física. Universidades. Memória.
Resumo: Fundamentado no aporte teórico-metodológico da História Oral, este texto analisa os dez Centros de Memória da Educação Física e Esporte existentes nas universidades federais brasileiras, considerando seus objetivos, funções e estratégias de ação. Para tanto, foram realizadas 36 entrevistas com pessoas que criaram e participaram dessas iniciativas, as quais foram cotejadas com outras fontes documentais. Ao analisarmos essas diferentes fontes, identificamos o quanto esses lugares são representados como espaços que guardam, recuperam, preservam, produzem e divulgam memórias. Por estarem vinculados a instituições universitárias outras funções são mencionadas, notadamente, no que se refere à produção de conhecimento e à formação de pessoas.
Keywords:

History. Physical Education. Universities. Memory.
Abstract: Based on the theoretical-methodological contribution of Oral History, this text analyzes the ten Memory Centers for Physical Education and Sports operating in Brazilian federal universities, considering their goals, functions and action strategies. Thirtysix interviews were conducted with the people who created and participated in those initiatives, which were compared with other documentary sources. In analyzing these different sources, the article discusses how these places are represented as spaces that keep, recover, preserve, produce and disseminate memories. Because they are linked to university institutions, other functions are mentioned, especially regarding knowledge production and training

Palabras clave: Historia. Educación Física. Universidades. Memoria.
Resumen: Fundamentado en el aporte teórico-metodológico de la Historia Oral, este texto analiza los diez Centros de Memoria de Educación Física y Deporte existentes en las universidades federales brasileñas, considerando sus objetivos, funciones y estrategias de acción. Para ello, fueron realizadas 36 entrevistas con personas que crearon y participaron en esas iniciativas, las cuales fueron verificadas con otras fuentes documentales. Al analizar las diferentes fuentes identificamos que esos lugares son representados como espacios que guardan, recuperan, preservan, producen y divulgan memorias. Por estar vinculados a instituciones universitarias, otras funciones son mencionadas, sobre todo en lo que se refiere a la producción de conocimiento y a la formación de personas.
*Universidade Federal do Vale do São Francisco. Petrolina, PE, Brasil. E-mail: christiane.macedo@univasf edu.br

**Universidade Federal do Rio Grande do Sul. Porto Alegre, RS, Brasil. E-mail: vilodre@gmail.com

Recebido em: 30-10-2018 Aprovado em: 26-04-2019 Publicado em: 13-06-2019

DOI: https://doi.org/10.22456/1982-8918.87769 (c) (1) (8) Licence Creative Commom 


\section{INTRODUÇÃOO}

Centros de Memória são espaços presentes em universidades, escolas, empresas e órgãos públicos que têm como função ampla a guarda de memórias institucionais, mesclando conhecimentos e características próprias de museus, arquivos e bibliotecas. No campo acadêmico-profissional da Educação Física brasileira, as primeiras iniciativas direcionadas para a criação desses lugares de memória (NORA, 1993) emergiram na década de 1990 em meio a um movimento de renovação historiográfica (TABORDA DE OLIVEIRA, 2007) cujo acontecer ampliou a noção de fonte, "o que, por sua vez, demandou outros olhares sobre os modos de produzi-las, inventariá-las, guardá-las e dar-lhes visibilidade e acessibilidade" (GOELLNER, 2013, p. 189). Tal movimento originou nas instituições universitárias a estruturação de ações voltadas para a produção, recuperação e preservação de fontes históricas, assim como a criação de grupos de pesquisa, instauração de linhas de investigação nos programas de pósgraduação e realização de eventos ${ }^{1}$ e publicações específicas².

Considerando esse contexto, o objetivo deste texto é analisar os Centros de Memória da Educação Física e Esporte (CMs) das universidades federais brasileiras, mais especificamente, questões relacionadas aos seus objetivos, funções e estratégias de ação. Para tanto, desenvolvemos uma pesquisa fundamentada na História Oral (ALBERTI, 2010), entendida aqui como uma metodologia de produção de fontes mediante a realização de entrevistas, envolvendo as seguintes etapas: gravação do áudio, transcrição, copidesque, pesquisa de termos, revisão pelo(a) entrevistado(a), assinatura de carta de cessão e publicação do documento transcrito ${ }^{3}$. Foram entrevistadas 36 pessoas que atuam ou atuaram nos dez CMs hoje existentes, cuja criação se deu entre os anos de 1996 e 2014. Considerando 0 número de pessoas envolvidas com esses lugares de memória, priorizamos entrevistar os(as) fundadores(as), coordenadores(as), professores(as) e técnicos(as) administrativos(as) que os integraram em sua fase inicial. A essas entrevistas agregamos outras com pessoas que neles tenham atuado por pelo menos dois anos. Esse corpo documental foi colocado em diálogo com outras fontes, mais especificamente, os projetos de criação dos CMs e as produções realizadas por suas equipes, tais como publicações no formato de livro, capítulos de livro, artigos, folhetos, guias, páginas de internet, programa de eventos científicos e culturais, entre outras. Para analisar esse corpus empírico, nos utilizamos das indicações de Pesavento (2005, p. 64) ao afirmar que é "[...] preciso recolher os traços e registros do passado, mas realizar com eles um trabalho de construção, verdadeiro quebra-cabeças ou puzzle de peças, capazes de produzir sentido".

Com o intuito de identificar as iniciativas de preservação da memória presentes nas universidades federais brasileiras, empreendemos um levantamento na internet, utilizando os termos "centro de memória", "memorial" e "arquivo histórico", os quais foram conjugados com "educação física", "esporte" e "universidade". A essa busca foram somadas outras ações, como, por exemplo, a pesquisa em produções acadêmicas, sites universitários e anais de eventos,

1 Merece destaque o Encontro Nacional de História da Educação Física e Esporte, que teve sua primeira edição na Universidade Estadual de Campinas, em 1996. O evento, que mudou o nome para Congresso de História do Esporte, do Lazer e da Educação Física (CHELEF), soma 15 edições, sendo a última realizada em novembro de 2018 em Curitiba/PR.

2 Dentre as várias publicações que emergiram no período, destacamos duas iniciativas: em 1996, Amarílio Ferreira Neto organizou a coleção Pesquisa Histórica em Educação Física, contendo seis volumes publicados nos anos de 1996, 1997, 1998, 1999, 2000 e 2001. Nos anos de 2003 e 2004, a Revista Brasileira de Ciências do Esporte, ligada ao Colégio Brasileiro de Ciências do Esporte, publicou dois volumes contendo o dossiê temático História da Educação Física.

3 Disponivel em: https://lume.ufrgs.br/handle/10183/40501. 
sobretudo, aqueles ligados à historiografia da Educação Física. Feito o entrelaçamento dessas fontes, foram encontrados dez CMs, conforme o quadro abaixo.

Quadro 1 - Centros de Memória das universidades federais

\begin{tabular}{|l|c|c|}
\hline \multicolumn{1}{|c|}{ Centro } & Sigla & Fundação \\
\hline Centro de Memória do Esporte & CEME/UFRGS & 1996 \\
\hline Centro de Memória da Educação Física, do Esporte e do Lazer & CEMEF/UFMG & 2001 \\
\hline Centro de Memória Inezil Penna Marinho & CMIPM/UFRJ & 2001 \\
\hline Centro de Memória da Educação Física e do Esporte no Nordeste & CEMEFEN/UFPB & 2002 \\
\hline Centro de Memória do Departamento de Educação Física & CEMEDEF/UFPR & 2004 \\
\hline Centro de Memória da Educação Física, do Esporte e do Lazer & CEMEFEL/UFS & 2005 \\
\hline Centro de Memória do Esporte e da Educação Física da Bahia & CEMEEFB/UFBA & 2008 \\
\hline Centro de Memória do Esporte e da Educação Física de Juiz de Fora & CEMEEF/UFJF & 2009 \\
\hline Centro de Memória da Educação Física e do Esporte & CEMEFE/UFMT & 2013 \\
\hline Memorial da Educação Física e do Esporte & Memorial do CEFD/UFSM & 2014 \\
\hline
\end{tabular}

Fonte: as autoras, 2018

Da análise do material empírico que ancora esta pesquisa, três dimensões foram frequentemente citadas como sendo aquelas que legitimam a existência de um Centro de Memória dentro de uma instituição universitária: a preservação da memória, a produção de conhecimento e a formação de pessoas. $O$ ato de preservar aparece organicamente imbricado com a produção de saberes cuja relevância se justifica pela possibilidade de evitar o desaparecimento de registros que narram aspectos históricos da Educação Física e do esporte em suas múltiplas dimensões.

\section{OS CENTROS DE MEMÓRIA DA EDUCAÇÃO FÍSICA E DOS ESPORTES: SABER PRESERVAR PARA PRESERVAR O SABER}

Pierre Nora (1993, p. 21), ao propor o conceito de "lugares de memória", explica que 0 termo assume que "[...] são lugares, com efeito nos três sentidos da palavra, material, simbólico e funcional, simultaneamente, somente em graus diversos". A preservação da memória foi a justificativa basilar para a criação de todos os CMs aqui analisados, o que pode ser observado inclusive na denominação atribuída a essas iniciativas: em nove delas figura o termo "memória" e em uma o derivativo "memorial", se relacionando aos sentidos simbólicos e funcionais desses espaços. Tal presença indica o quanto a intencionalidade de produzir, preservar e guardar acervos se fazia imperante no processo de edificação desses espaços e está relacionada ao que se projetava como seus objetivos e funções. Linhales e Nascimento, ao refletirem sobre a denominação do CEMEF/UFMG referem-se à sua funcionalidade:

De todo modo, o costume corriqueiro de adotar o termo Centro de Memória encontra-se ligado a uma vocação do Centro para a preservação da memória da Educação Física, do Esporte e do Lazer, mesmo sabendo que a memória é dispersa, dinâmica, objeto de disputas e, portanto, passível de ressignificações (LINHALES; NASCIMENTO, 2013, p. 7).

A memória é aqui entendida como sendo "uma produção do passado sob a luz da experiência vivida" (MELO; DRUMOND, 2013, p. 161), um testemunho, uma espécie de fiador da existência de um passado (CHARTIER, 2010) cuja elaboração é constantemente 
revivida, reelaborada e modificada. Segundo Camargo e Goulart (2015), a palavra memória nos CMs reflete tanto a característica de evocar experiências passadas como o suporte para registros e a recuperação dessas experiências. Ou seja, a vocação para preservar foi o mote para a constituição dos acervos desses CMs que, apesar de possuírem suas singularidades, preservam algo em comum:

[eles] abrigam vestígios de outros tempos cuja adoção como fonte possibilita reconstruir histórias plurais. Histórias que focalizam não apenas as instituições e os acontecimentos mas, também, as pessoas. Em especial aquelas cuja intervenção vislumbrou possibilidades estratégicas de guardar para não perder (MACEDO; GOELLNER, 2018, p. 34).

Os acervos que compõem esses CMs são significados como elementos propulsores desse rememorar, um suporte de identidade capaz de justificar ou fortalecer as reivindicações de vários grupos, entidades e associações (MENESES, 1999). O ato de rememorar integra os objetivos explicitados nos projetos inaugurais desses CMs, conforme pode ser observado no quadro a seguir:

Quadro 2 - Verbos-chave nos objetivos dos CMs

\begin{tabular}{|c|c|c|c|c|c|c|}
\hline $\mathrm{CM}$ & \multicolumn{6}{|c|}{ Verbos-chave nos objetivos dos CMs } \\
\hline UFRGS & Preservar & Recuperar & Divulgar & $\begin{array}{c}\text { Organizar } \\
\text { acervos }\end{array}$ & Pesquisar & Organizar eventos, dar acesso \\
\hline UFMG & Preservar & Recuperar & Divulgar & $\begin{array}{l}\text { Organizar } \\
\text { acervos }\end{array}$ & Pesquisar & $\begin{array}{c}\text { Armazenar, criar acervos } \\
\text { específicos }\end{array}$ \\
\hline UFRJ & Preservar & Recuperar & Divulgar & & Pesquisar & Disponibilizar \\
\hline UFPB & Preservar & & & & Pesquisar & \\
\hline UFPR & Preservar & Recuperar & Divulgar & & & \\
\hline UFS & Preservar & & Divulgar & & & Debater \\
\hline UFMT & Preservar & & & Servir como fonte & & \\
\hline UFSM & & Resgatar & & & Pesquisar & Servir ao ensino \\
\hline UFBA & \multicolumn{6}{|c|}{ Não encontrado } \\
\hline UFJF & \multicolumn{6}{|c|}{ Não encontrado } \\
\hline
\end{tabular}

Fonte: as autoras, 2018.

Preservar, recuperar, divulgar e pesquisar foram metas recorrentes, evidenciando que o tema da memória, aqui organicamente vinculado à produção de acervos, demandava não apenas seu recolhimento e guarda, mas, também, a elaboração de estratégias de divulgação e utilização para fins de produção de conhecimento. O uso da palavra "preservar" está profundamente relacionado com a perspectiva de evitar a perda de registros, de acervos, de memórias e de histórias. Tal percepção está alinhada com os conceitos-chave da Museologia, conforme determinação do Conselho Internacional de Museus:

Preservar significa proteger uma coisa ou um conjunto de coisas de diferentes perigos, tais como a destruição, a degradação, a dissociação ou mesmo 0 roubo; essa proteção é assegurada especialmente pela reunião, o inventário, o acondicionamento, a segurança e a reparação. Na museologia, a preservação engloba todas as operações envolvidas quando um objeto entra no museu, isto é, todas as operações de aquisição, entrada em inventário, catalogação, acondicionamento, conservação e, se necessário, restauração (DESVALLÉES; MAIRESSE, 2013, p. 79). 
Preservar, no contexto dos CMs analisados, implicou ações de recuperação e resgate. Dessa forma, vemos a íntima relação entre os sentidos trazidos por Nora (1993), vinculando assim, o sentido simbólico (ser reconhecido como lugar de memória), ao funcional (atuar para sua preservação) ou material (possuir registros de memória). Nesse sentido, a primeira estratégia adotada pelos CMs foi a localização e recolha dos arquivos institucionais ligados aos cursos de formação em Educação Física dos departamentos e/ou unidades acadêmicas nos quais esses Centros se localizavam. Vera Moro ${ }^{4}$ relata que tão logo se constituiu o CEMEDEF/ UFPR, a primeira ação empreendia foi a transferência do arquivo da Escola de Educação Física e Desportos do Paraná, que se encontrava em um local praticamente abandonado desde 1978, momento no qual aconteceu a federalização da Escola dando origem ao Departamento de Educação Física da UFPR. Nas suas palavras: "Simplesmente as pessoas pediam para usar, o secretário dava as chaves, as pessoas entravam e tentavam identificar. E realmente era uma situação bastante precária" (MORO, 2016, p. 5).

A busca pelos arquivos institucionais integrou o rol de atividades do CEMEFE/ UFMT. Atuando como bolsistas de graduação, Talita Ferreira $(2014)^{5}$ descreve o processo de localização de documentos da instituição cuja existência estava gravemente ameaçada.

Fizeram uma espécie de um rebaixado com um portãozinho com uma grade de ferro embaixo do ginásio e colocaram tudo lá dentro, quando eu abri tinha muitas caixas estragadas, porque o pessoal da limpeza, limpa o ginásio e joga água e esse lugar é um lugar aberto, a água escorre para dentro desse local, colocaram até um tapume para colocar as caixas em cima, madeira, madeira e água, cupim, tinha muito cupim, já estava num estado de decomposição até algumas caixas (FERREIRA, 2014, p. 5).

Além da busca pelos arquivos institucionais, identificamos outras iniciativas visando a busca por acervos: o CEME/UFRGS, o CEMEF/UFMG, o CEMEFEL/UFS e o CEMEDEF/UFPR fizeram contato pessoal ou telefônico com pessoas e instituições que poderiam ter acervos relacionados ao seu escopo, assim como enviaram correspondência solicitando doações. Em 1997, os(as) docentes em atividade e aposentados(as) da Escola de Educação Física da UFRGS receberam uma carta ${ }^{6}$ que informava sobre a proposta de criação do Centro de Memória e ao mesmo tempo requeria contribuições: "Neste sentido, solicitamos a colaboração de Vossa Senhoria em doar documentos e objetos, como: registros escritos, fotografias, vídeos, troféus e outros. Solicitamos também contato ou indicação de pessoas que possam contribuir com doações".

O CEMEDEF/UFPR também utilizou um recurso semelhante. André Capraro ${ }^{7}$ relata em sua entrevista:

O que eu posso contar de iniciativa minha durante o período que estive lá... Muito inocente, já que não sabia direito como funcionava o Centro de Memória, junto com os estagiários, tive a seguinte ideia: vamos começar a solicitar doações dos próprios professores, sobretudo os mais velhos, para o nosso Centro. Na semana

\footnotetext{
4 Entrevista realizada em 24/11/2016, via Skype (internet), a entrevistada estava na Universidade Federal do Paraná, na cidade de Curitiba/ PR e a entrevistadora em sua residência em Porto Alegre/RS. A entrevista teve duração de 51 minutos e 34 segundos. Vera foi criadora do CEMEDEF/UFPR, coordenando seus projetos.

5 Entrevista realizada em 13/11/2014, na Escola de Educação Física, Fisioterapia e Terapia Ocupacional (UFMG), na cidade de Belo Horizonte/MG, com duração de 44 minutos e 28 segundos. O encontro se deu durante o Seminário do CEMEF de 2014. Talita é vinculada ao CEMEFE/UFMT e participou de seus primeiros projetos, como aluna de graduação e mestrado, atualmente é pesquisadora desse CM.

6 MAZO, Janice Zaperllon. Carta com solicitação de doações, com lista de recebimento. Universidade Federal do Rio Grande do Sul. Escola de Educação Física. Centro de Documentação. Acervo CEME. Porto Alegre, 6 jun. 1997 [Documento não publicado].

7 Entrevista realizada em 27/09/2014, na Universidade Federal do Paraná, Campus Litoral, na cidade de Matinhos/PR, com duração de 34 minutos e 21 segundos. $O$ encontro se deu durante o Congresso Sul-brasileiro de Ciências do Esporte de 2014. André foi vinculado ao CEMEDEF/UFPR, como coordenador e pesquisador.
} 
seguinte, chegaram caixas e mais caixas de provas, pois todo mundo é obrigado a guardar. Pilhas e pilhas... (2014, p. 10).

Além dos acervos obtidos por meio de solicitações como essas, vários CMs receberam doações espontâneas de pessoas que os reconheciam como lugares nos quais aquilo que estava sendo cedido seria preservado, retomando o sentido simbólico que estes lugares possuem. Cesar Leiro ${ }^{8}$, ao relembrar o processo de criação do CEMEEFB/UFBA, menciona:

Um episódio que eu acho importante destacar foi que eu recebi o convite de alguns professores para visitar suas residências, professores mais velhos, professores importantes da história da Educação Física da Bahia, e recebi atas, convites de formatura e outros documentos para um dia poder tecnicamente socializar (2017, p. 4).

Para além dessas ações de recolha de documentos da própria instituição e da solicitação de doação de acervos, identificamos outras empreitadas em busca de memórias materiais e imateriais. O CEME/UFRGS, o CEMEF/UFMG, o CEMEFE/UFMT e o CEMEEFB/ UFBA, por exemplo, desenvolveram projetos fundamentados na realização de entrevistas com ancoragem na História Oral. $\mathrm{O}$ depoimento de docentes e servidores técnico-administrativos que atuaram nas instituições sedes foram amplamente registrados. Talita Ferreira (CEMEFE/ UFMT) em sua entrevista destaca essa ação:

Eu me sentia uma depositária, fiel depositária como diz no direito, das histórias e memórias desses professores. [...] Eu me senti muito importante, apesar de estar fazendo um trabalho para a Universidade, isso me tocou profundamente, porque eu entrei em contato com pessoas que eu não vi mais, o professor, eu vi o homem, eu vi o pai, eu vi o amigo, eu vi o colega, eu vi a pessoa triste, eu fiquei sabendo do momento mais feliz da vida dele ali dentro, isso me tocou muito $(2014$, p. 14).

Estratégia similar foi adotada pelo CEMEEFB/UFBA ao produzir vídeos contendo entrevistas com pessoas reconhecidas no cenário da Educação Física na Bahia. Cesar Leiro (2017) destaca dois deles: o primeiro realizado com Maria Helena Affonso de Carvalho, conhecida como Dona laiá, uma das professoras mais antigas de Educação Física na Bahia, e o segundo intitulado "Trio Regina: o aroma da Educação Física tradicional da Bahia" contendo entrevistas com Alcir Ferraro, Fernando José da Cunha Chagas e Nilton Miranda, professores da Universidade Católica de Salvador na década de 1970, o primeiro curso de nível superior da área.

Ao analisarmos essas formas de captação e produção de acervos, percebemos que está profundamente imbricada a ideia de evitar o apagamento, a destruição e a perda de bens patrimoniais, reconhecidos como importantes para a história da Educação Física brasileira. Nas palavras de Cesar Leiro:

[...] o maior presente que nós podemos dar, no caso específico para a Educação Física, é a constituição de um espaço que possa fazer com que a gente reflita sobre o nosso passado. Portanto, sem os Centros de Memória, o futuro nosso da Educação Física não tem muita possibilidade no presente (2017, p. 13).

Ana Carrilho Grunennvaldt ${ }^{9}$ (CEMEFE/UFMT) faz a mesma ressalva ao mencionar que "o Centro de Memória ele é passado, ele é presente, ele é futuro e não se desfaz uma

8 Entrevista realizada em 12/01/2017, via Skype (internet), o entrevistado estava na Universidade Federal da Bahia, na cidade de Salvador/ $\mathrm{BA}$ e a entrevistadora em residência de familiares em Goiânia/GO. A entrevista teve duração de 33 minutos e 36 segundos. César foi criador do CEMEEFB/UFBA, coordenando seus projetos. 
coisa da outra" (2016, p. 13). Essa representação mantém profunda relação com as atribuições apontadas por Gomes para os centros de memórias acadêmicos, visto que os considera como "[...] espaços para guarda dos registros de memória coletiva, que se apresentam com 0 importante papel de resgate da cultura de uma dada sociedade ou instituição social, por meio da seleção de fatos, dados e informações a serem preservados para a posteridade" (2015, p. 10).

No intuito de cumprir tais atribuições, mostrou-se assídua nos CMs da área da Educação Física a intencionalidade de divulgar e pesquisar aquilo que seria guardado. Tarcísio Vago ${ }^{10}$, ao discorrer em sua entrevista sobre a experiência do CEMEF/UFMG, destaca:

\begin{abstract}
[...] o Centro só se constitui na medida em que há pesquisas em andamento, em que há estudos em andamento, nós não queríamos fazer disto aqui um depósito de livros, e de objetos, de equipamentos, nós queríamos ter esse duplo movimento, reunir, guardar, preservar, mas também pesquisar, estudar, produzir conhecimento sobre história da Educação Física, do esporte e do lazer e para isso era preciso sentar, ler, discutir, apresentar uns para os outros os seus estudos, as suas pesquisas [...] (VAGO, 2014, p. 16).
\end{abstract}

Essa afirmação visibiliza o caráter diferencial de um lugar de memória instituído dentro de uma universidade que implica, ainda, a vinculação com o ensino, a pesquisa e a extensão. Nessa direção, fez-se necessário agregar novos objetivos, dentre eles o de investigar, uma vez que "[...] o processo de investigação amplia as possibilidades de comunicação do bem cultural e dá sentido à preservação" (CHAGAS, 1994, p. 39).

Dentre os dez CMs existentes, identificamos a existência de uma profunda relação com a produção de conhecimento. O CEMEEFB/UFBA e o CEMEF/UFJF se constituíram a partir de grupos de pesquisa já existentes na instituição. O CEMEF/UFMG, o CEMEFEN/UFPB e o CEMEFEL/UFS estão registrados no Diretório dos Grupos de Pesquisa no Brasil, do Conselho Nacional de Desenvolvimento Científico e Tecnológico, e o CEME/UFRGS é vinculado ao Grupo de Estudos sobre Esporte, Cultura e História (GRECCO).

Ao analisarmos o material empírico que ancora esta pesquisa, nos deparamos com uma larga diversidade de produtos originários dos modos de pesquisar: livros e capítulos, artigos científicos, produções acadêmicas, entrevistas, sites, blogs, guias, materiais didáticos, inventários, mostras fotográficas, exposições, entre outros. Um destaque pode ser feito: dada a estreita relação dos(as) docentes que criaram e que atuam nos CMs com a pesquisa historiográfica, identificamos, dentre as produções de seus membros, várias relacionadas à história da instituição na qual o Centro se localiza. São exemplares dessa afirmação trabalhos publicados por integrantes do CEME/UFRGS (MAZO; Pereira, 2005; Macedo et al, 2010), CEMEF/UFMG (KANITZ JÚNIOR, 2003; LINHALES, 2013), CMIPM/UFRJ (MELO, 1996) ${ }^{11}$, CEMEDEF/UFPR (SILVA; CAPRARO, 2011), CEMEFEL/UFS (MENEZES, 1997), CEMEF/ UFJF (CUNHA JÚNIOR; MARTINS; ZACARIAS, 2003) e CEMEFE/UFMT (FERREIRA, 2015). Tal propósito pode ser identificado não apenas como uma maneira de conhecer a própria história, mas de "[...] fortalecer sua identidade interna e externa e de compreender mais claramente seu papel e o de seu corpo funcional nos novos cenários, com vistas a uma adaptação mais bemsucedida" (FONTANELLI, 2005, p. 80-81).

\footnotetext{
10 Entrevista realizada em 18/11/2014, na Escola de Educação Física, Fisioterapia e Terapia Ocupacional, da Universidade Federal de Minas Gerais. Tarcísio é criador do CEMEF/UFMG e atualmente pesquisador deste CM. A entrevista teve duração de 1 hora 17 minutos e 43 segundos. 11 Além da própria página de internet que não está mais disponível, que continha informações sobre a Escola Nacional de Educação Física e disponibilizava parte do seu acervo.
} 
$\mathrm{Na}$ tentativa de valorizar a história institucional, identificamos ainda algumas iniciativas empreendidas pelos CMs de reconhecer suas trajetórias por meio de celebrações, fundamentalmente, em datas que remetem à fundação das unidades e/ou departamentos de Educação Física aos quais estão vinculados. Em 1996, o CEME/UFRGS participou da organização de uma atividade comemorativa aos 50 anos da biblioteca setorial da Escola de Educação Física, assim como exposições temáticas celebrando os aniversários de 60, 65 e 70 anos da instituição (comemorados no dia 6 de maio de 2000, 2005 e 2010). Antes de ser criado o CEMEF/UFJF, foi realizado um movimento de valorização das memórias da instituição por ocasião do aniversário de 30 anos do curso de Educação Física. 0 resultado desse movimento foi a publicação do livro Educação Física: memórias e narrativas em Juiz de Fora (CUNHA JUNIOR, MARTIN; ZACARIAS, 2003), para o qual foi necessária a busca de acervos pessoais e institucionais. Marco Acosta ${ }^{12}$ (Memorial do CEFD/UFSM) recorreu à organização de exposições para chamar a atenção sobre a importância da memória institucional. "No hall a gente fez exposições de fotos, naquele modelo bem assim de cordel, sabe, fotos penduradas, foi uma das coisas interessantes, fizemos duas vezes" (2016, p. 5).

Tais iniciativas agregam uma das dimensões assumidas pelos CMs, qual seja, 0 "seu papel celebrativo, como local de exposição e de monumentalização de experiências e personalidades de destaque na história institucional" (SANTOS; VENÂNCIO, 2015, p. 78). Ao visualizarmos as ações colocadas em funcionamento por estes lugares de memória, percebemos que a tríade "preservar, recuperar e divulgar", explicitada nos seus objetivos, conforma um modo de existência profundamente relacionado a instituições museais que, segundo Joseph Veach Noble (1970), possui cinco funções: colecionar, conservar, estudar, interpretar e expor. Quando relacionadas com a universidade, algumas especificidades ganham foco nesse modo de existir, visto que "referem-se a memórias de comunidades acadêmicas caracterizadas por suas áreas de conhecimento e atuação específicas" (BICALHO, 2013, p. 2). Preservar, estudar e transmitir (VAN MENSCH apud POULOT, 2013) conjugam saberes e fazeres que informam não apenas os objetivos desses CMs, como também o entendimento daquilo que eles são e 0 que representam. Segundo Santiago,

Esses Centros de Memória contribuem com o restauro, a preservação e disponibilização dos acervos nos centros de pesquisa propriamente e por meio da elaboração de sites, principalmente com aqueles que recuperam e disseminam dados relacionados com a história da Educação Física, do esporte e do lazer (2010, p. 95-96).

Consoante seus objetivos, funções e ações, destacamos que os CMs exercem um papel político de extrema relevância: registrar algo já acontecido e, de certo modo, fazê-lo perdurar em outros tempos e contextos culturais. No entanto, por estarem vinculados a instituições universitárias e quase todos manterem proximidade com grupos de pesquisa, outra dimensão ganha notoriedade: a formação de pessoas.

Reconhecer esse papel implica entender que não se caracterizam apenas como lugares de memória, mas também e principalmente como espaços em que o conhecimento é produzido, "em que existe a possibilidade de traduzir a experiência e construir verdades, mesmo que essas verdades pareçam irremediavelmente redundantes, superficiais e próximas ao lugar-comum" (GIROUX; MCLAREN, 1995, p. 144).

12 Entrevista realizada em 02/12/2016, via Skype (internet), o entrevistado estava em sua residência na cidade de Santa Maria/RS e a entrevistadora em residência de familiares em Goiânia/GO. Marco é professor da Universidade Federal de Santa Maria e foi criador do 
Fernanda Santos ${ }^{13}$, a falar sobre o papel do CEMEF/UFMG em sua trajetória, afirma: "a minha própria formação como professora de Educação Física e como pesquisadora da História da Educação Física é perceptível os saltos que a gente dá e as coisas que a gente aprende, tanto para a carreira quanto para a vida" (2014, p. 13). Cássia Lima ${ }^{14}$, integrante desse Centro há dez anos, ao descrever sua experiência, enfatiza:

O CEMEF tem sua trajetória marcada pela formação de professores/pesquisadores. Professores que nos diferentes níveis de ensino saem daqui interrogando suas práticas cotidianas. E isso só se faz possível porque se desenhou enquanto lugar de reflexões e possibilidades de encontros - encontros com diferentes trajetórias, com diferentes formas de pensar e organizar o ensino, o encontro com a história de seu ofício. Possibilitando a construção de um fazer orientado por uma dimensão ética - de respeito à história do outro, de uma visão de mundo mais humana $e$ solidária, do desejo de transformar, de fazer diferente, de iluminar... (2016, p. 3).

$\mathrm{Na}$ fala de algumas pessoas entrevistadas, os CMs apareceram com espaços de formação e de sociabilidade. Tal característica está associada à existência dos grupos de pesquisa, os quais, em grande medida, desenvolvem ações coletivas que extrapolam a investigação individual de cada participante. Para Cássia Lima:

Criamos relações firmes, consolidadas, que extrapolam as questões circunscritas ao centro... Professores em formação, professores mais experientes, do ensino básico, do ensino superior estabelecem uma relação de ajuda mútua, de cumplicidade, orientada pelo compromisso com a EF e com o humano (2016, p. 6).

A sociabilidade aqui é entendida como um espaço de encontro, convivências, realização, aprendizados cotidianos e trocas afetivas. Leila Mattos ${ }^{15}$, servidora técnico-administrativa ligada ao CEME/UFRGS, ao tentar defini-lo expressa: "é um Centro de Memória do Esporte que eu acho que agrega tudo. Agrega os acervos, agrega arquivos, agrega pesquisa, agrega extensão, agrega pessoas, agrega afinidades de diversidades de pessoas, grupos de pessoas" (2015, p. 29). Tais falas e todas as que trouxemos a este texto demonstram o quanto esses espaços são plurais, dinâmicos e estão em permanente construção.

\section{CONSIDERAÇÕES FINAIS}

A representação como "lugares de memória", pode ser associada aos dez CMs aqui analisados, pois a cada um deles podem ser atribuídos os três sentidos apresentados por Pierre Nora (1993). Eles são reconhecidos como lugares de preservação de memórias pela comunidade em que atuam e, ainda que tenham particularidades, todos possuem materialidade seja pela presença de acervos físicos e virtuais, seja por existirem em um espaço próprio, mesmo que por vezes pequeno e inadequado à dimensão de seus objetivos. Além disso, esses CMs vêm cumprindo as funções assumidas, sobretudo, aquelas direcionadas para a preservação e difusão de memórias e histórias da Educação Física e do esporte.

\footnotetext{
13 Entrevista realizada em 17/11/2014, na Escola de Educação Física, Fisioterapia e Terapia Ocupacional, da Universidade Federal de Minas Gerais. Fernanda é participante do CEMEF/UFMG e foi estudante de graduação e mestrado, vinculada a esse CM. A entrevista teve duração de 46 minutos e 13 segundos.

14 Cassia Danielle Monteiro Dias Lima disponibilizou o documento base para sua fala na Mesa "O CEMEF e a formação de professores/ pesquisadores" no IX Seminário do Centro de Memória da Educação Física do Esporte e do Lazer: Formação, Investigação e Organização do Acervo, que ocorreu em 2016 [Documento não publicado]. 
Para suas funções se destaca o fato de serem universitários, assumindo assim outras ações e características desses espaços, relacionando ensino, pesquisa e extensão. Ainda assim uma ressalva deve ser feita: nenhum dos CMs analisados se constitui como um órgão permanente das universidades que integram. Todos estão relacionados a iniciativas individuais e de grupos cuja continuidade depende dos seus esforços no sentido de garantir 0 financiamento não apenas das pesquisas, mas de uma estrutura que permita manter o espaço físico, os equipamentos e as pessoas que neles são formadas. Se o saber a ser preservado depende da preservação do saber, a análise dessas dez iniciativas indica o quão significativa é a intencionalidade política e pedagógica das pessoas que os fizeram e fazem acontecer. Suas narrativas, aqui relembradas, focalizam uma particularidade da história da Educação Física brasileira: a preocupação com a memória.

\section{REFERÊNCIAS}

ACOSTA, Marco Aurélio. Depoimento de Marco Aurélio Acosta: Projeto Garimpando Memórias, Santa Maria (RS), p. 1-12, 02 dez. 2016. Entrevista concedida a Centro de Memória do Esporte - ESEF/UFRGS (Entrevistadora: Christiane Garcia Macedo). Disponível em: https:// lume.ufrgs.br/handle/10183/157426. Acesso em: 16 mar. 2019.

ALBERTI, Verena. Histórias dentro da História. In: PINSKY, Carla Bassanezi (Org.). Fontes históricas. 2. ed. São Paulo: Contexto, 2010. p. 155-202.

BICALHO, Lucinéia Maria. Centro de Memória da Farmácia da UFMG: uma experiência interdisciplinar. In: ENCONTRO NACIONAL DE PESQUISA EM CIÊNCIA DA INFORMAÇÃO, 14., GT-9 - Museu, Patrimônio e Informação, 2013, Rio de Janeiro. Anais [...]. Rio de Janeiro: 2013, p. 1-9. Disponível em: http://repositorios.questoesemrede.uff.br/repositorios/ handle/123456789/2563. Acesso em: 5 mar. 2017.

CAMARGO, Ana Maria; GOULART, Silvana. Centros de Memória: uma proposta de definição. São Paulo: Edições Sesc São Paulo, 2015.

CAPRARO, André Mendes. Depoimento de André Mendes Capraro: Projeto Garimpando Memórias, Matinhos (PR), p. 1- 14, 27 set. 2014. Entrevista concedida a Centro de Memória do Esporte - ESEF/UFRGS (Entrevistadora: Christiane Garcia Macedo). Disponível em: https:// lume.ufrgs.br/handle/10183/109612. Acesso em: 16 mar. 2019.

CHAGAS, Mário de Souza. Em busca do documento perdido: a problemática da construção teórica na área da documentação. Cadernos de Museologia, n. 2, p. 29-47, 1994. Disponível em: http:// recil.grupolusofona.pt/jspui/bitstream/10437/3511/3/Em\%20busca.pdf. Acesso em: 23 out. 2018.

CHARTIER, Roger. A História ou a leitura do tempo. 2. ed. Belo Horizonte: Autêntica Editora, 2010.

CUNHA JUNIOR, Carlos Fernando Ferreira da; MARTIN, Edna; ZACARIAS, Lígia (orgs.). Educação Física: memórias e narrativas em Juiz de Fora. Juiz de Fora: EDUFJF, 2003.

DESVALLÉES, André; MAIRESSE, François (eds.). Conceitos-chave de Museologia. São Paulo: Comitê Brasileiro do Conselho Internacional de Museus; Pinacoteca do Estado de São

Paulo; Secretaria de Estado da Cultura, 2013. 
FERREIRA, Talita. Depoimento de Talita Ferreira: Projeto Garimpando Memórias, Belo Horizonte (MG), p. 1 - 20, 13 nov. 2014. Entrevista concedida a Centro de Memória do Esporte - ESEF/UFRGS (Entrevistadora: Christiane Garcia Macedo). Disponível em: https://lume.ufrgs.br/ handle/10183/143186. Acesso em: 16 mar. 2019.

FERREIRA, Talita. A educação física e o esporte no estado de Mato Grosso: uma odisseia biográfica do professor João Batista Jaudy. 2015. 234f. Dissertação (Mestrado em Educação Física) - Faculdade de Educação Física, Universidade Federal do Mato Grosso, Cuiabá, 2015.

FONTANELLI, Silvana Aparecida. Centro de Memória e Ciência da Informação: uma interação necessária. 2005. 106f. Trabalho de Conclusão de Curso (Graduação em Biblioteconomia) - Universidade de São Paulo, São Paulo, São Paulo, 2005. Disponível em: http://www.rabci.org/rabci/sites/default/files/Fontanelli-Memoria.pdf. Acesso em: 16 jan. 2017.

GIROUX, Henry A.; MCLAREN, Peter L. Por uma pedagogia crítica da representação. In: SILVA, Tomaz Tadeu da; MOREIRA, Antônio Flávio (Orgs.) Territórios Contestados: 0 currículo e os novos mapas políticos e culturais. Petrópolis: Vozes, 1995. p. 144-158.

GOELLNER, Silvana Vilodre. O CEMEF/UFMG: partilhando experiências, produzindo saberes, inspirando sonhos. In: LINHALES, Meily Assbú; NASCIMENTO, Adalson (Orgs.). Organizando arquivos, produzindo nexos: a experiência de um Centro de Memória. Belo Horizonte: Editora Fino Trato, 2013. p. 187-194.

GOMES, Clausi Maria do Porto. Centros de memória acadêmicos: um estudo de multicasos na UFMG. 2015. 156f. Dissertação (Mestrado em Ciência da Informação) - Escola de Ciência da Informação, Universidade Federal de Minas Gerais, Belo Horizonte, 2015.

GRUNENNVALDT, Ana Carrilho Romero. Depoimento de Ana Carrilho Romero Grunennvaldt: Projeto Garimpando Memórias, Cuiabá (MT), p. 1- 16, 20 maio 2016. Entrevista concedida a Centro de Memória do Esporte - ESEF/UFRGS (Entrevistadora: Christiane Garcia Macedo). Disponível em: https://lume.ufrgs.br/handle/10183/157421. Acesso em: 16 mar. 2019.

KANITZ JUNIOR, R. M. Escola de Educação Física de Minas Gerais (1950-1958): o começo de uma história. 2003. 107f. Trabalho de conclusão de curso. (Graduação em Educação Física) - Universidade Federal de Minas Gerais, Belo Horizonte, 2003.

LEIRO, Augusto Cesar Rios. Depoimento de Augusto César Rios Leiro: Projeto Garimpando Memórias, Salvador (BA), p. 1-14, 12 jan. 2017. Entrevista concedida a Centro de Memória do Esporte - ESEF/UFRGS (Entrevistadora: Christiane Garcia Macedo). Disponível em: https:// lume.ufrgs.br/handle/10183/158331. Acesso em: 16 mar. 2019.

LINHALES, Meily Assbú; NASCIMENTO, Adalson (orgs.). Organizando arquivos, produzindo nexos: a experiência de um Centro de Memória. Belo Horizonte: Fino Trato, 2013.

LINHALES, Meily Assbú. Modelos Pedagógicos, Formação Docente e Práticas Escolares: o ensino da Educação Física na cidade de Belo Horizonte (1947-1977). In: CONGRESSO BRASILEIRO DE HISTÓRIA DA EDUCAÇÃO, 7, 2013, Cuiabá. Anais [...]. Cuiabá: 2013. Disponível em: http://sbhe.org.br/novo/congressos/cbhe7/pdf/06-\%20HISTORIA\%20DAS\%20 CULTURAS\%20E\%20DISCIPLINAS\%20ESCOLARES/MODELOS\%20PEDAGOGICOS.pdf . Acesso em: 21 mar. 2019.

MACEDO, Christiane Garcia et al. "llhas de lembranças": Histórias e Memórias dos 70 anos da Escola Superior de Educação Física da Universidade Federal do Rio Grande do Sul-ESEF/ UFRGS. In: CONGRESSO SULBRASILEIRO DE CIÊNCIAS DO ESPORTE, 5. 2010, Itajaí (SC). 
Anais [...]. Itajaí: 2010. Disponível em: http://congressos.cbce.org.br/index.php/sulbrasileiro/vcsbce/ paper/view/2091/1033. Acesso em: 21 mar. 2019.

MACEDO, Christiane Garcia; GOELLNER, Silvana Vilodre. Guardar para não perder: a constituição dos acervos dos Centros de Memória da Educação Física nas universidades federais brasileiras. RIDPHE_R Revista Iberoamericana do Patrimônio Histórico-Educativo, v. 4, n. 1 , p. 20-37, 2018.

MATTOS, Leila de Carneiro. Depoimento de Leila Carneiro Mattos: Projeto Garimpando Memórias, Porto Alegre (RS), p. 1 - 30, 19 mar. 2015. Entrevista concedida a Centro de Memória do Esporte - ESEF/UFRGS (Entrevistadora: Christiane Garcia Macedo). Disponível em: https://lume.ufrgs.br/handle/10183/156588. Acesso em: 16 mar. 2019.

MAZO, Janice Zaperllon; PEREIRA, Priscilla Goulart. Escola de Educação Física da Universidade Federal do Rio Grande do Sul. In: MAZO, Janice Zaperllon; REPPOLD FILHO, Alberto Reinaldo (Orgs.). Atlas do Esporte no Rio Grande do Sul: atlas do esporte, Educação Física e atividades de saúde e lazer no Rio Grande do Sul. Porto Alegre: CREF2/RS, 2005. Disponível em: http://www.crefrs.org.br/atlas/cd/texto/esef.pdf. Acesso em: 15 jun. 2017.

MELO, Victor Andrade de. Escola Nacional de Educação Física e Desportos: uma possível história. 1996. 207f. Dissertação (Mestrado em Educação Física) - Universidade Estadual de Campinas, Campinas, 996.

MELO, Victor Andrade de; DRUMOND, Maurício. Pesquisa histórica e história do esporte. Rio de Janeiro: 7 letras, 2013.

MENESES, Ulpiano T. Bezerra. A crise da memória, história e documento: reflexões para um tempo de transformações. In: SILVA, Zélia Lopes da (org.). Arquivos, patrimônio e memória: trajetórias e perspectivas. São Paulo: Ed. Unesp; FAPESP, 1999. p. 11-30.

MENEZES, José Américo Santos. Escola de Educação Física da Universidade Federal de Sergipe: uma possível história. 1997. 155f. Dissertação (Mestrado em Educação) - PósGraduação em Educação, Universidade Federal de Sergipe, São Cristóvão, 1997.

MORO, Vera Luiza. Depoimento de Vera Luiza Moro: Projeto Garimpando Memórias, Curitiba (PR), p. 1 - 18, 24 nov. 2016. Entrevista concedida a Centro de Memória do Esporte - ESEF/ UFRGS (Entrevistadora: Christiane Garcia Macedo). Disponível em: https://lume.ufrgs.br/ handle/10183/157438. Acesso em: 16 mar. 2019.

NOBLE, Joseph Veach. Museum Manifesto. Museum News, n. 48, n. 8, p. 17-20, abr.1970.

NORA, Pierre. Entre memória e história: a problemática dos lugares. Revista do Programa de Estudos Pós-Graduados em História e do Departamento de História, n. 10, p. 7-28, dez. 1993.

PESAVENTO, Sandra Jatahy. História \& história cultural. 2. ed. Belo Horizonte: Autêntica, 2005.

POULOT, Dominique. Museu e museologia. Belo Horizonte: Autêntica, 2013.

SANTIAGO, Danilo R. P. Impacto dos projetos, sob o olhar dos pesquisadores. In: SCHWARTZ, Gisele Maria et al. Gestão da informação sobre esporte recreativo e lazer: balanço da Rede CEDES. Várzea Paulista: Fontoura, 2010. p. 93-102. 
SANTOS, Fernanda Cristina dos. Depoimento de Fernanda Cristina dos Santos: Projeto Garimpando Memórias, Belo Horizonte (MG), p. 1 - 14, 17 nov. 2014. Entrevista concedida a Centro de Memória do Esporte - ESEF/UFRGS (Entrevistadora: Christiane Garcia Macedo). Disponível em: https://lume.ufrgs.br/handle/10183/139183. Acesso em: 16 mar. 2019.

SANTOS, Silvana; VENÂNCIO, Renato. Arquivos institucionais e memória da Universidade Federal de Minas Gerais: um estudo dos arquivos de arquitetura. In: NASCIMENTO, Adalson; MORENO, Andrea (orgs.). Universidade, memória e patrimônio. Belo Horizonte: Mazza, 2015. p. 59-82.

SILVA, Marcelo Moraes; CAPRARO, André Mendes. O contexto de fundação da Escola de Educação Física e Desportos do Paraná: educando corpos para a vida urbana. Revista Brasileira de Ciências do Esporte, v. 33, n. 3, p. 623-636, 2011.

TABORDA DE OLIVEIRA, Marcus Aurélio. Renovação historiográfica na Educação Física brasileira. In: SOARES, Carmen Lúcia (org.). Pesquisas sobre o corpo: Ciências humanas e educação. Campinas: Autores Associados, 2007. p. 117-138.

VAGO, Tarcísio Mauro. Depoimento de Tarcísio Mauro Vago: Projeto Garimpando Memórias, Belo Horizonte (MG), p. 1 - 26, 18 nov. 2014. Entrevista concedida a Centro de Memória do Esporte - ESEF/UFRGS (Entrevistadora: Christiane Garcia Macedo). Disponível em: https:// lume.ufrgs.br/handle/10183/118783. Acesso em: 16 mar. 2019.

\section{Apoio:}

O presente trabalho foi realizado com apoio da Coordenação de Aperfeiçoamento de Pessoal de Nível Superior, Brasil (CAPES) - Código de Financiamento 001. This study was financed in part by the Coordenação de Aperfeiçoamento de Pessoal de Nível Superior - Brasil (CAPES) Finance Code 001. 